\title{
Seasonal timing using put option portfolio protection on the Johannesburg Securities Exchange
}

\section{INTRODUCTION}

Market timing is generally described as a strategy of switching between asset classes in anticipation of significant economic changes. In contrast to selecting individual securities for a portfolio, market timing seeks to switch or weight entire portfolios into particular asset classes.

Jeffery (1984), in his seminal article titled "The Folly of Stock Market Timing", showed that perfect timing ability in switching between an equity index on the NYSE and cash for the period 1926 - 1982 would have produced an annualised return of $10,8 \%$ above the S\&P 500 return. However, he noted that if all timing decisions were incorrect, the return would have dropped to $17,6 \%$ below that of the S\&P 500 . He concluded that the risks assumed by market timer were not in proportion to the incremental rewards that could be gained. The maximum potential losses were almost double the maximum potential upside gains. Jeffrey (1984:102) commented that "no one can predict the market's ups and downs over a long period, and the risks of trying outweigh the rewards".

Despite this warning, researchers noted that the upside potential (and downside risk) increased with shorter timing intervals, and equally significantly, the risk reduced for accurate timers (see for example Firer, Sandler, Ward (1992)). Shorter timing intervals incur greater transaction costs, and to minimise these, strategies involving derivatives were investigated (see Hanson (1984)).

In particular, Waksman, Sandler, Ward and Firer (1997) showed that a market timing strategy using put options to hedge a portfolio over short review periods offered an attractive risk/return trade-off. They concluded that a strategy of buying monthly put options on the JSE Securities Exchange (JSE) all share index (ALSI) required a forecasting accuracy of only $50,7 \%$ (i.e. to select the appropriate months) to have an equal chance of beating the buy-and-hold the index, and offered large upside potential (p88).

Many of these timing strategies appear to be potentially attractive. However, to reduce costs and to be of use to practitioners most require a trading rule of some sort to indicate when to switch or hedge asset classes. Amongst other indicators, the seasonal characteristics of a market can provide a useful timing

*Graduate School of Management, University of Pretoria, Pretoria 0001, Republic of South Africa.

Email: Mike.ward@up.ac.za rule. One of the more striking claims for a profitable trading rule is made by Jacobsen and Bouman (2001) who claim that the adage "Sell in May and go away but buy back on St Leger Day"1 has merit. Jacobsen and Bouman (2001), analysing more than 30 years of stock market data on 19 major markets showed that, in every instance, the average return for the half year November to April exceeded that of May to October.

This paper explores a market timing strategy on the JSE using seasonality as an indicator of when to switch (or hedge) an index portfolio.

\section{LITERATURE REVIEW}

Eugene Fama's (1970) efficient market hypothesis (EMH) formed a popular and beguiling platform for securities research and academics. Even the socalled "weak form" of the EMH suggests that share prices fully incorporate historical trading data and therefore technical analysis and (most) trading rules are of little material value. Following this, analysts should focus on the economic, sectoral and company specific prospects ('fundamental analysis') and ignore past share price trends and patterns. Until the reemergence of behavioural theory (de Bondt and Thaler (1985) and others) research into historical trading patterns and rules was relegated to the area of "market anomalies".

Many authors have reported seasonal attributes of stock market returns. One of the more outstanding features is the so-called January effect. Rozeff and Kinney (1976), using US market data from 1904 to 1974 , first noted that the mean daily return in January was $0,0348 \%$, significantly higher than the next highest month, July, at 0,0190\%. Subsequent work by other authors found a significant association with size (the effect being more pronounced for smaller companies) and more recent work, Riepe (1998), (2001), has indicated that excess returns in January may be declining.

\footnotetext{
${ }^{1}$ The origins of the "Sell in May but buy back on St Leger day" are unclear. St Leger refers to a horse race, the St Leger Classic, founded in September 1776 by Lieutenant Colonel Anthony St. Leger, a successful Irish soldier who later became Governor of St Lucia. The Classic has taken place every year since 1776, except 1939, when the race was cancelled due to the outbreak of the Second World War (BBC Sport, 2001).
} 


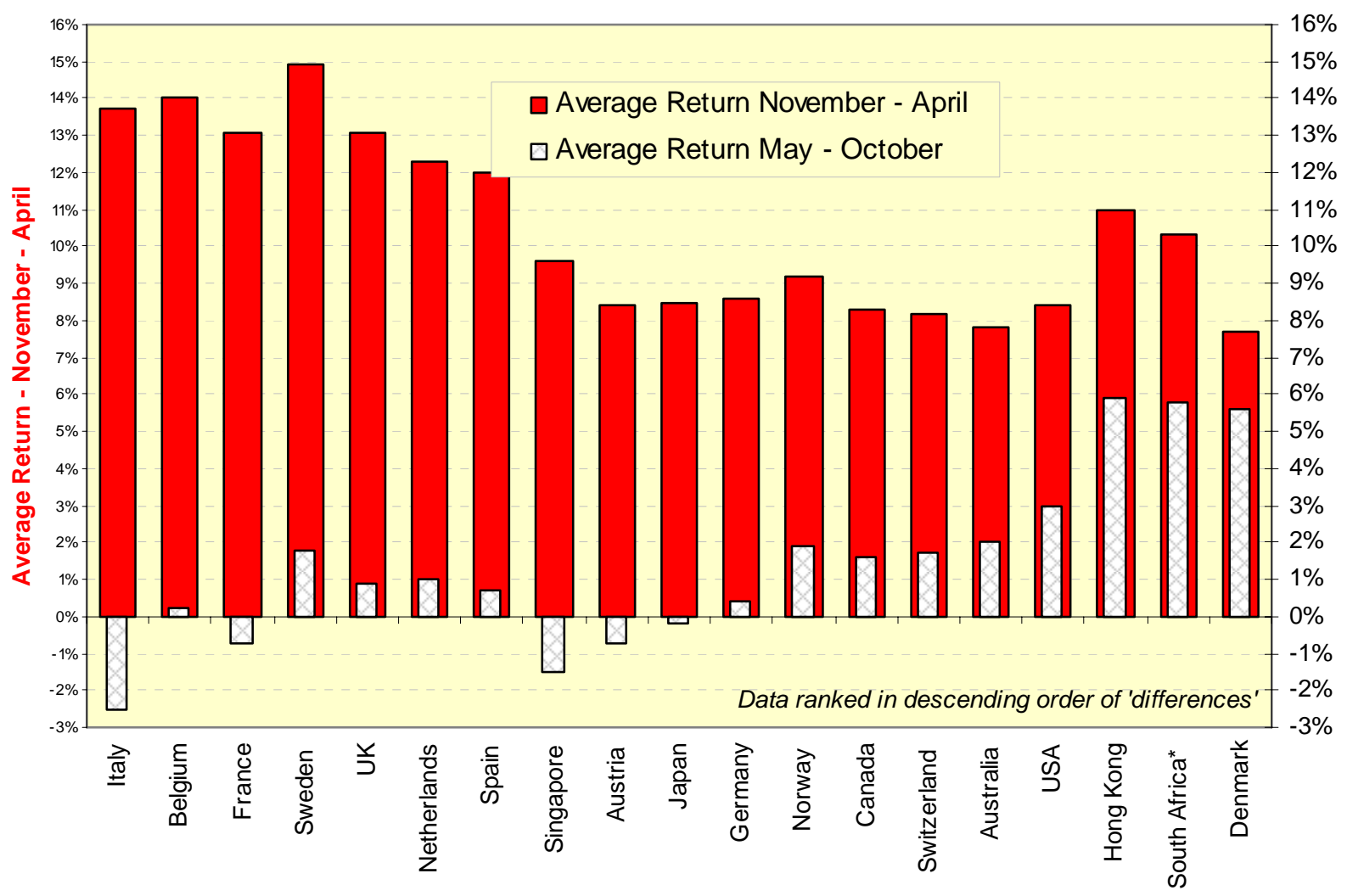

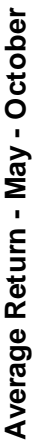

Figure 1: Average returns over two 6 month periods for major markets, January 1970 to August 1998

The graph shows that in all 19 major markets the average return between November and April significantly exceeds that of May to October. Similar results were found by other researchers for all major markets except New Zealand.

Source: MSCI Indices with dividends reinvested, local currency. From Bouman \& Jacobsen (2001). *Returns for South Africa date from 1973.

Mills and Coutts (1995), investigating UK data, found the mean return in January was the largest of any month over the January 1986 - October 1992 period. Similarly, Van Den Berg and Wessels (1985), investigating the Amsterdam Stock Exchange between January 1966 and December 1982, reported an annualised January mean return of $4,39 \%$, significantly higher than any other month. Canestrelli and Ziemba (2000) reported January the best month for the Milan stock exchange. In Japan, Comolli and Ziemba (2000) found January returns to be considerably higher than other months.

Ho (1990), analysing the 1975-1987 period for 12 markets including the US and UK, identified ten with significantly higher January returns: Hong-Kong, Japan, Korea, Malaysia, Philippines, Singapore, Taiwan and Thailand, as well as the UK and USA.

Robins, Sandler and Durand (1999) reported evidence of a January effect, independent of a value or market capitalisation effect, on the JSE for the period 1986 1995. Beeders (2000) reported a strong (first five days of) January effect on the JSE for the period 1988 to 1999. Coutts and Sheik (2000), examining the gold sector of the JSE, reported a January return which is negative although statistically insignificant from zero.
Although the studies mentioned above focused on January, many of them report April and February as being above average, suggesting a seasonality greater than a single month, and this is the foundation of Jacobsen and Bouman's (2001) claim. Jacobsen and Bouman (2001) find that, in 36 out of 37 equity markets, significantly better economic returns (on a risk adjusted and after transaction cost basis) are achieved by timing the market to be in equities from November to April and switching to cash from May to October. They show that the rule persists in the UK market since 1694, in the US since 1802, in France since 1900 and in Japan since 1920 . The only major market in which they find the rule not to hold is New Zealand.

Lucey and Whelan (2002), using an alternative dataseries for the Irish market from 1934 to 1999, examine the Jacobsen and Bouman (2001) evidence. They report (p16) that the average return in the half-year to end April is 2,6\% higher than the half-year to end October over the period 1934-69, and the gap widens in more recent times to average $7,1 \%$ over the whole period. The authors provide extensive evidence using random designs and non-parametric tests and conclude: "the returns in the first half of the year, from November to April, are greater in magnitude to those 
of the second half of the year in all but the 1946-57 period. The Kruskal-Wallis test does not indicate that this effect is statistically significant but the ANOVA test does. This is true in all bar one sub-period, and from the Levene test, this cannot be attributed to differential risk profiles within these periods" (p30).

Sullivan, Timmerman and White (2001) dismiss the claim of statistical significance of this or any other calendar-based trading rule, attributing the results to data-mining. They state: "We find that although nominal $p$-values of individual calendar rules are extremely significant [i.e. pointing to a low probability that the result is due to mere chance], once evaluated in the context of the full universe from which such rules were drawn, calendar effects no longer remain significant" (p251). The authors argue that the assumptions underlying classical inferential statistics are invalidated through the use of the same data set to formulate and test hypotheses. With this in mind, the intention of this paper is to (largely) avoid inferential statistics and significance testing and focus on economic significance.

\section{METHODOLOGY}

The objective of this study is to test for seasonality on the JSE. The null hypothesis states that (tradable) seasonality does not exist on the JSE to the extent that a market timing strategy might be fruitful. The alternative hypothesis states that a trading rule, along the lines of a period in the market and the remaining period in cash, is valuable. A variation on the alternative hypothesis is to purchase put options on the index ("portfolio insurance") in place of switching to cash.

The monthly total equity return data for the ALSI Index and the return on cash, derived by Firer and Mcleod (discussed in Firer \& Staunton (2003)), for the JSE from 1925 to 1959 were supplemented by monthly data from 1960 to June 1995, sourced from JP Morgan $^{2}$. From June 1995 to 2001 the JSE daily indicative total return index, and from 2002, the JSE actual daily total return index, was used for the equity return portfolio. Where available, daily data were used in the analysis. Figure 2 shows the average monthly total return on the index over the entire period by month.

Figure 2 shows that on average for the period 1925 2005, June and October are the worst months, with December and January being the best. It is worth noting that, over the latter portion of the data (from 1960 -2005), the high January effect is less evident than what is reflected in Figure 2 as a result of

\footnotetext{
${ }^{2}$ Prime less $3 \frac{1}{2} \%$ was used as the proxy for the risk-free rate for the data from January 1960 . The $3 \frac{1}{2} \%$ spread was estimated from the historical spread for prime over the 90 day NCD rate for the past decade (1995 - 2005)
}

significant market crashes in 1981, 1988 and 1995. It should also be noted that the data contains outliers, with major stock market crashes in October, January and elsewhere (see Table 1 for more statisitics). Having established a reasonable basis for a seasonal pattern in the data, and following Jacobsen and Bouman (2001), a simple market timing strategy was established: "Invest in the equity index for six months and in cash for the following six months".

Using (the more reliable) data from 1960 - 2005, the total return for the six months in the market was calculated from the index and the cash return was taken as (Prime $-3 \frac{1}{2} \%$ ). The value of R1 invested in symmetrical (reversed) portfolios of either cash or the index for 6 months was then compared to a buy-andhold the index strategy. The switching date between cash and the index was then changed on a day by day basis to identify the optimal switching dates. The results are shown in Figures 3 and 4 and Table 2 below:

Figure 3 shows the average out-performance between the two portfolios for different switching days in the year. It can be observed that day 339 ( $4^{\text {th }}$ December) represents the optimal switching date into equities. Figure 4 shows that it is possible to match the 'buy and hold the index' position with such a strategy, with the optimal period to be in the market from $4^{\text {th }}$ December to the $4^{\text {th }}$ June. Table 2 shows that this strategy of switching has a marginally lower risk (standard deviation and modified Sharpe's ratio $^{3}$ ) than the benchmark 'buy and hold the index'. Optimising the period in the market (i.e. with non-symmetrical portfolios) showed that being in the market for eight months from November to August, and in cash in September, October and November provided a strategy which significantly out-performed the index.

These promising results indicated scope for investigating a more comprehensive hedging strategy. Fund managers find it impractical to switch asset classes in the manner described above for several reasons. These would include the fact that transaction costs are significant; taxation considerations are an issue; it may be difficult to sell and buy large holdings of shares and there is discomfort at being completely out of the market. For these reasons it was decided to explore a hedging strategy using put options against the industrial index. These can be purchased in a customised form over-the-counter from various banks or in a standardised form on the futures market (SAFEX). Given the time-span of the data it was necessary to estimate option prices, since these did not exist for most of the period under consideration.

\footnotetext{
${ }^{3} \mathrm{~A}$ modified Sharpe's ratio was calculated as (portfolio return/portfolio standard deviation)
} 


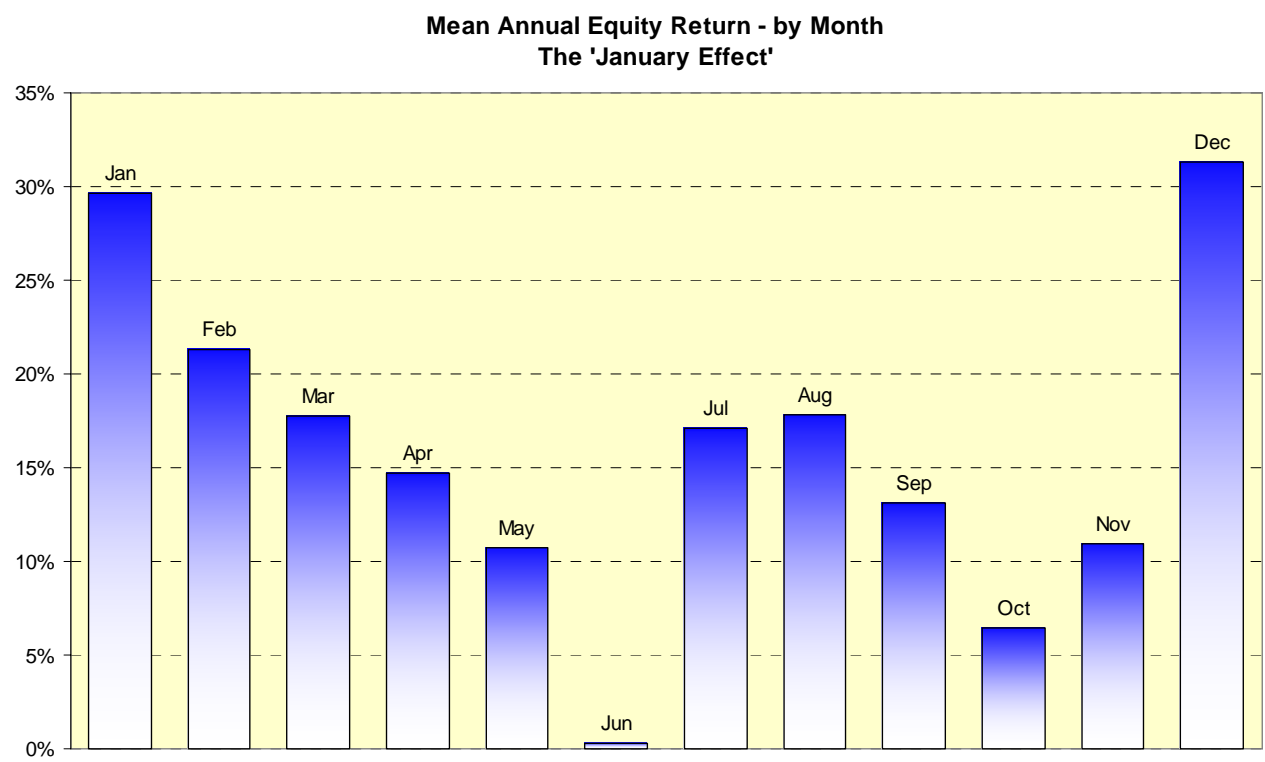

Figure 2: Mean annual equity returns by month $1925-2005$

The graph shows that the lowest returns typically occur in June and October, with the best months being December and January. A distinct 'January Effect' is evident from the graph.

Table 1: Monthly return statistics 1925 - 2005 on the JSE total return index

The table shows that the highest returns have occurred in December and January, the lowest in August and October, and the market has been most volatile in January and August.

\begin{tabular}{|c|c|c|c|c|c|c|c|c|c|c|c|c|}
\hline & Jan & Feb & Mar & Apr & May & Jun & Jul & Aug & Sep & Oct & Nov & Dec \\
\hline Min & $-13,5 \%$ & $-8,2 \%$ & $-14,5 \%$ & $-9,8 \%$ & $-18,0 \%$ & $-12,6 \%$ & $-13,1 \%$ & $-29,3 \%$ & $-12,7 \%$ & $-23,5 \%$ & $-16,9 \%$ & $-6,9 \%$ \\
\hline $\operatorname{Max}$ & $23,7 \%$ & $13,1 \%$ & $17,3 \%$ & $11,8 \%$ & $14,1 \%$ & $11,2 \%$ & $13,2 \%$ & $18,9 \%$ & $15,5 \%$ & $14,2 \%$ & $12,2 \%$ & $18,6 \%$ \\
\hline Mean & $2,4 \%$ & $1,5 \%$ & $1,3 \%$ & $0,8 \%$ & $1,0 \%$ & $0,2 \%$ & $1,2 \%$ & $1,6 \%$ & $1,1 \%$ & $0,7 \%$ & $0,7 \%$ & $2,4 \%$ \\
\hline Std Dev & $6,1 \%$ & $3,7 \%$ & $5,2 \%$ & $4,5 \%$ & $4,8 \%$ & $4,7 \%$ & $4,6 \%$ & $6,1 \%$ & $4,7 \%$ & $5,1 \%$ & $4,5 \%$ & $4,9 \%$ \\
\hline
\end{tabular}

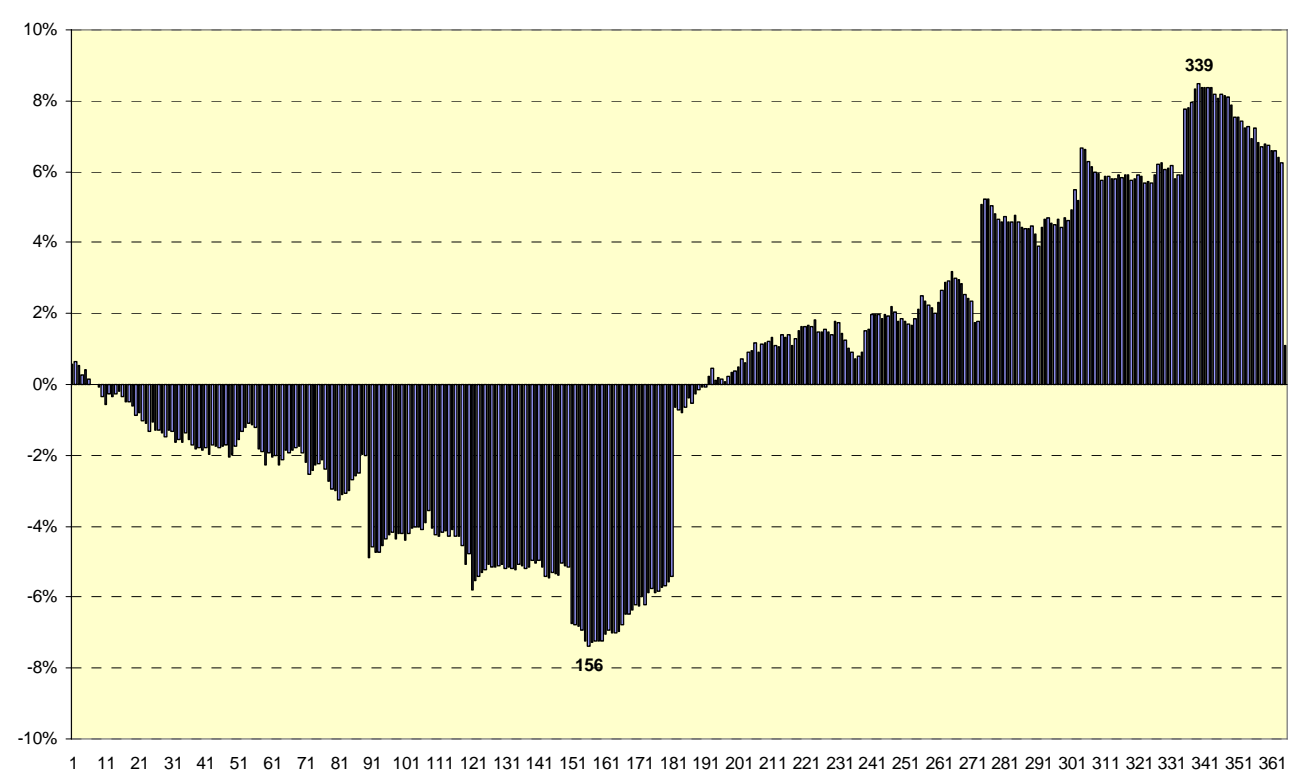

Figure 3: Under/over-performance between alternative strategies of being in cash or equities for 6 months of the year with different switching dates

The graph shows the under/over-performance of the total return index from 1960 to 2005. The returns of the two portfolios are symmetrical. Day 339 (December $4^{\text {th }}$ ) is shown to be the optimal day to switch into equities, returning to cash on the $4^{\text {th }}$ June (day 156) (i.e. 6 months later). 


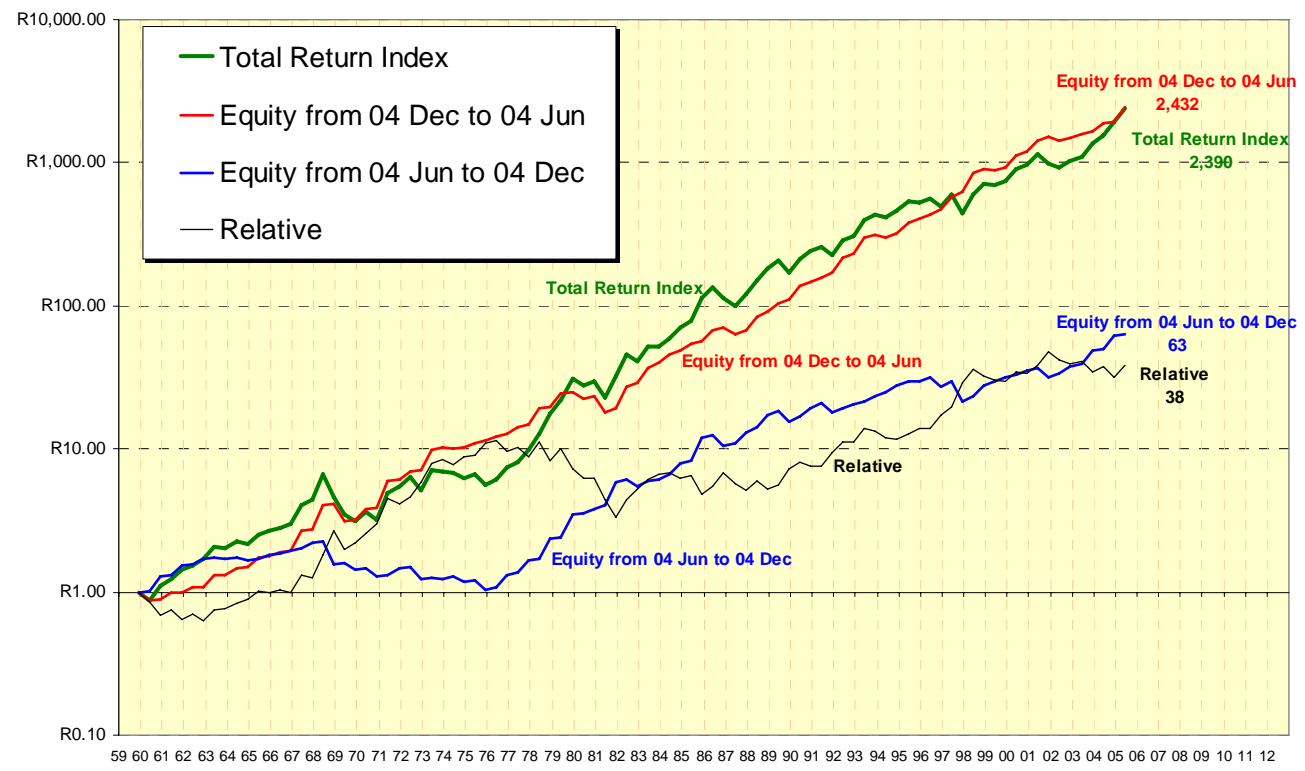

Figure 4: Returns from portfolios invested in equity (cash) from $4^{\text {th }}$ December to $4^{\text {th }}$ June and cash (equity) from $4^{\text {th }}$ June to $4^{\text {th }}$ December

The figure shows the value of R1 invested from $31^{\text {st }}$ December 1959 to $31^{\text {st }}$ December 2005 . The performance of the optimal portfolio is very similar to that of the index, but significantly out-performs the alternate strategy, suggesting that material seasonality exists. No transaction costs were considered.

Table 2: Monthly performance statistics for two portfolios and the index over the period 1960 2005.

The table shows that portfolio one (equity from $4^{\text {th }}$ December to $3^{\text {rd }}$ June and cash from $4^{\text {th }}$ June to $3^{\text {rd }}$ December) out-performs the index on a risk adjusted basis with a higher modified Sharpe's ratio.

\begin{tabular}{lccc}
\hline & Portfolio One & Portfolio Two & Index \\
\hline Min & $-28,30 \%$ & $-36,50 \%$ & $-36,50 \%$ \\
Max & $42,90 \%$ & $36,20 \%$ & $42,90 \%$ \\
Mean & $8,40 \%$ & $4,60 \%$ & $8,40 \%$ \\
Std Dev & $11,70 \%$ & $12,40 \%$ & $16,80 \%$ \\
Mod Sharpe & 0,72 & 0,37 & 0,50 \\
\hline
\end{tabular}

The Black-Scholes option pricing model was used to value the puts. Two strategies were investigated: buying at-the-money (ATM) puts for the duration of the month and a "crash protection" strategy of buying $10 \%$ out-the-money puts for the duration of the month. The returns on cash (described earlier) were used as the risk-free rate and volatility was estimated using the prior month's daily returns (where daily data was available i.e. 1985 - 2005) or the prior 12 monthly returns (where only monthly data was available i.e. 1925-1984). To account for any skewness or kurtosis in the return distribution, a volatility premium was added. The volatility premium was estimated by "goal-seeking" the slope of the performance relative line (i.e. the performance of the hedged portfolio/performance of the index) to approximate zero; the assumption being that over a long period of time the market would correctly price puts such that a strategy of purchasing put options in every period would be reward neutral. For example, in the instance of the $10 \%$ out-the-money 'crash protection' strategy, for the period 1960 to 2005, a volatility premium of $2,1 \%$ was added to account for the "fat-tail" in the distribution. The volatility premium was re-estimated for analysis using the method described.

All the combinations of buying puts (i.e. combinations of months) were then tested against the entire data set and the performance of the portfolio compared with the buy-and-hold the index strategy. The outperformance data were ranked and the results analysed for the at-the-money strategy and for the 'crash-protection' strategy. Figures 5 and 6 present the findings for the ATM monthly put strategy.

The optimal hedging strategy for the at-the-money puts was to purchase options in April, June, August and October; in all other months the purchase of the put option decreased the average return or added only marginal value (see Figure 5). This strategy yielded an annualised out-performance of 1,07\% (see Figure 6), with a R1 investment in 1925 yielding R125 255 versus R52 441 for the buy-and-hold the index. Closer examination of the data showed that a strategy of buying an 8 month put from April to October would have performed almost as well, although this would not have allowed the strike price to ratchet-up in the bull runs typically evidenced prior to a market crash. Figure 6 also shows a performance-relative indicator, which shows that the strategy only out-performed in the latter portion of the data, since 1970; prior to this it under-performed. 


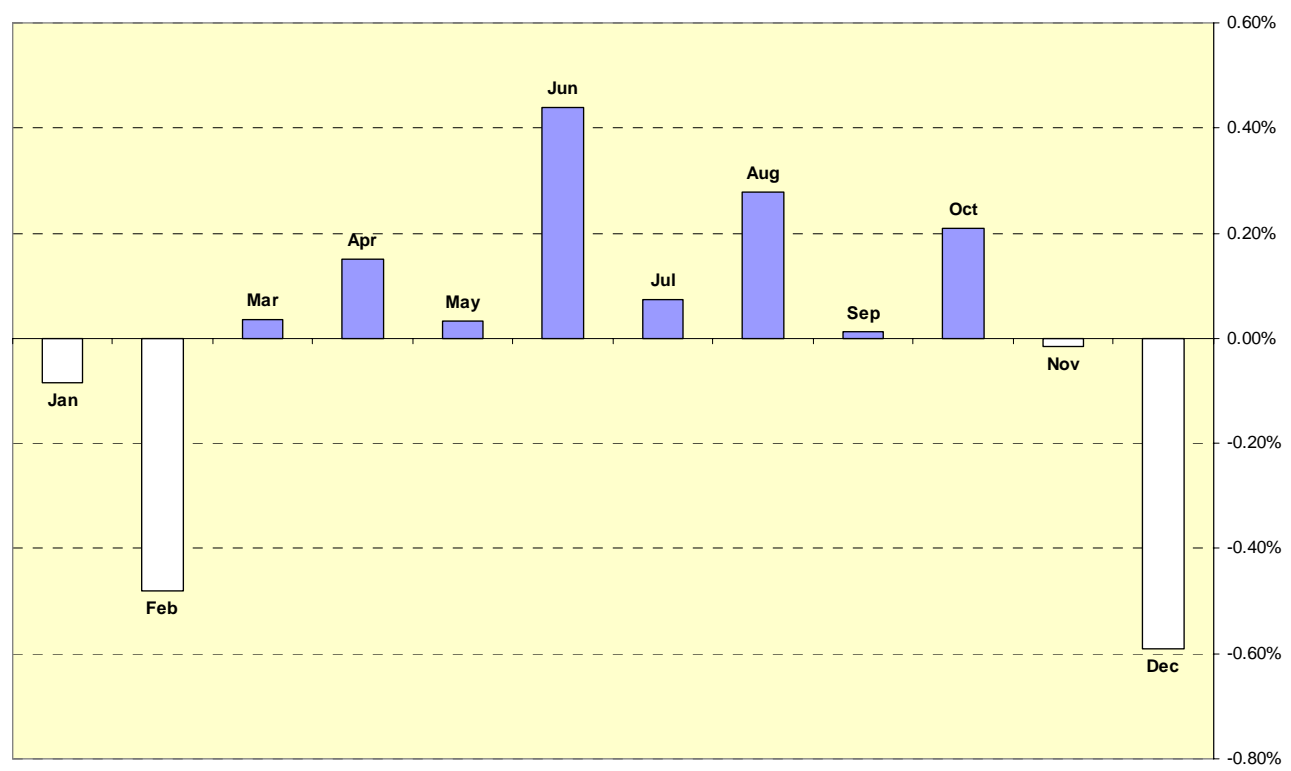

Figure 5: Monthly out-performance of at-the-money put options over the period $1925-2005$ The graph shows that ATM puts should be purchased in April, June, August and October, with March, May, July and September being marginal.

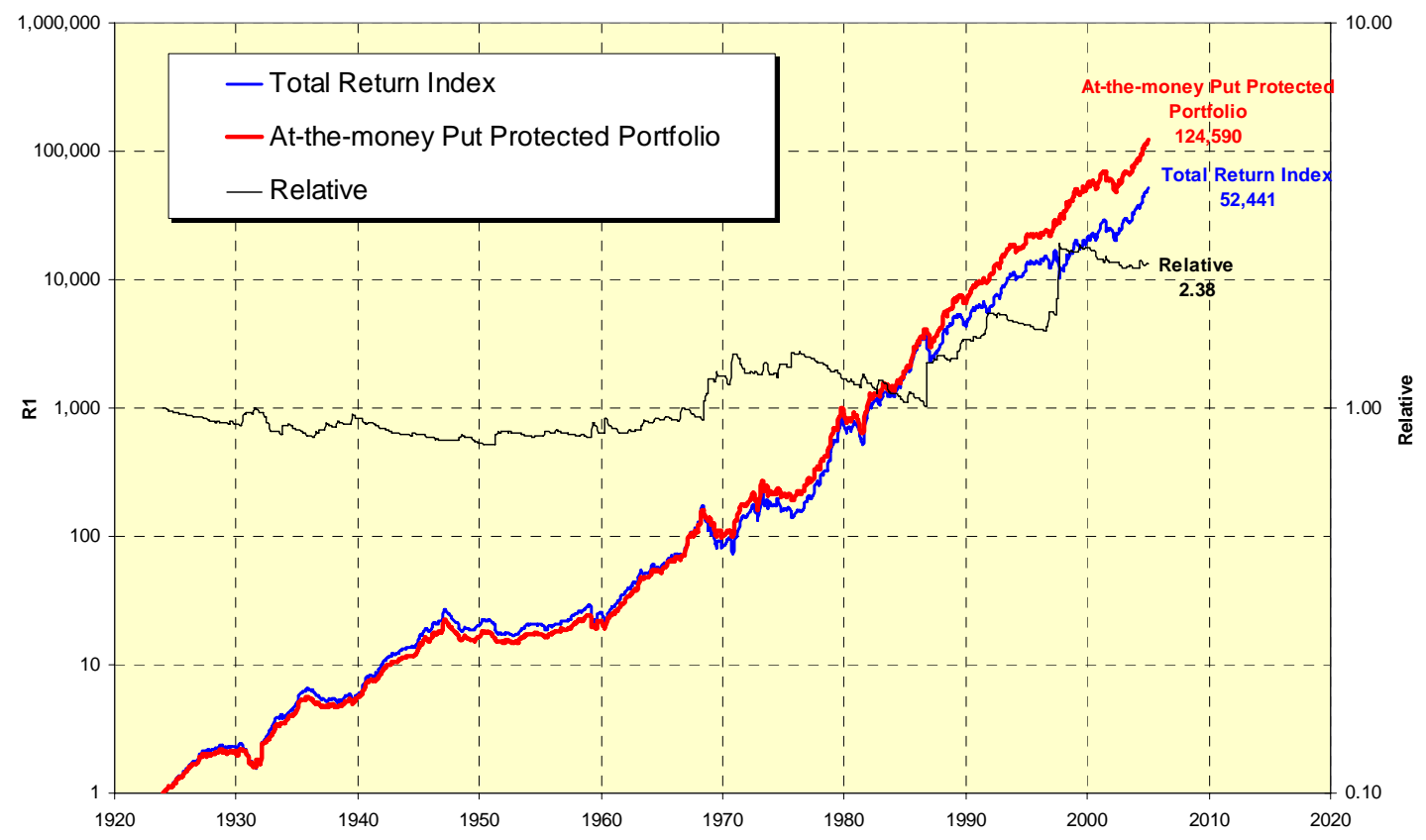

Figure 6: The performance of an at-the-money protected portfolio

The graph shows the value of R1 invested in the total return index from 1925 to 2005 if protected using ATM puts in April, June, August and October. Using this strategy the value of R1 would increase to R125 255 versus the index value of R52 441. The 'relative' performance indicator suggests that the strategy only works for the latter period of the data. 


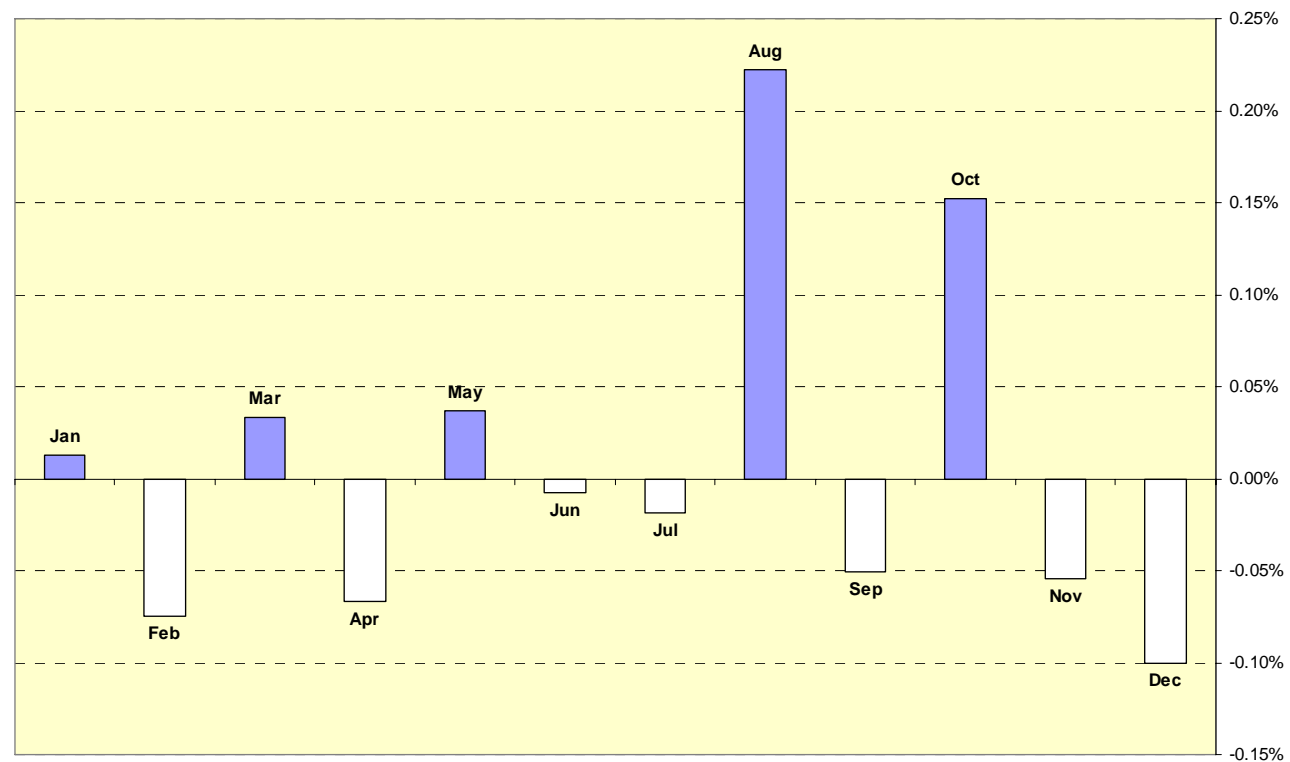

Figure 7: Monthly out-performance of $10 \%$ out-the-money put options over the period $1925-2005$

The graph shows that the 10\% OTM puts should be purchased in August and October, with January, March and May being marginal.

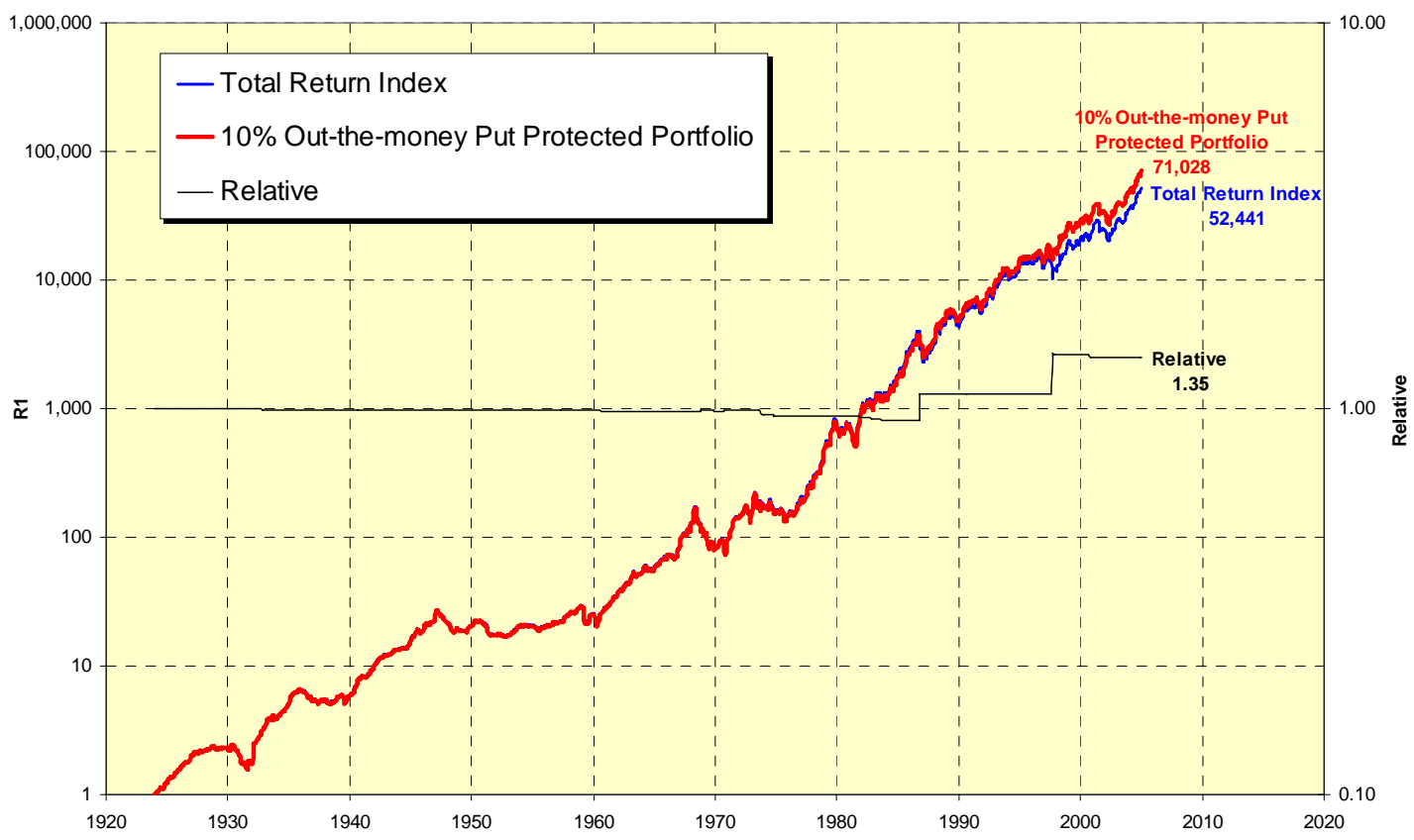

Figure 8: The performance of a $10 \%$ out-the-money crash protected portfolio

The graph shows the value of R1 invested in the total return index from 1925 to 2005 if protected using 10\% outthe-money puts in August and October. The puts were valued using B-S but with an $8 \%$ volatility premium to correct for the 'fat-tails' incurred using such a strategy. Using this approach the value of R1 would increase to R71028 versus the index value of R52 441. The 'relative' performance indicator suggests that the strategy only works for the crashes of 1987 and 1997. 
Figures 7 and 8 present the findings of the 'crashprotection' strategy, i.e. purchasing 10\% out-themoney puts. Whilst the pattern of seasonality is similar to that shown in Figure 5, the purchase of crash protection only added value in two months; August and October (see Figure 7). Over the entire period the strategy out-performed the index by a marginal, annualised $0,38 \%$ with a R1 investment in 1925 reflecting a value of R71 028 on $31^{\text {st }}$ December 2005. The price relative shows that the strategy underperformed most of the period, from 1925 to 1987. The market crashes of 1987 and 1998 were the only occasions in which the puts were valuable.

This above analysis was repeated to test for reliability using only the more reliable data from December $31^{\text {st }}$ 1984 to 2005. The results were similar, with August and October consistently showing as significant months in which to hedge. Once again the ATM approach produced superior results to the out-themoney crash protection strategy.
Given the importance that volatility plays in pricing options, the seasonality in volatility was further examined. Using the total returns index from December $31^{\text {st }} 1984$ to 2005, the trailing month's volatility was used to estimate the volatility in the following month. Figure 9 presents the results.

Figure 9 shows the maximum, average and minimum volatility estimates for each month. It is interesting to note that the lowest volatility occurs in the middle of the year, with a significant peak in October. A paired t-test indicated that the difference in volatility between June and October was significant $(t=2,3$ and $p=0,03)$.

Given the timing and extent of the different volatilities, an alternative hedging strategy was mooted. To illustrate this, Table 3 below shows the value of various put option strategies.

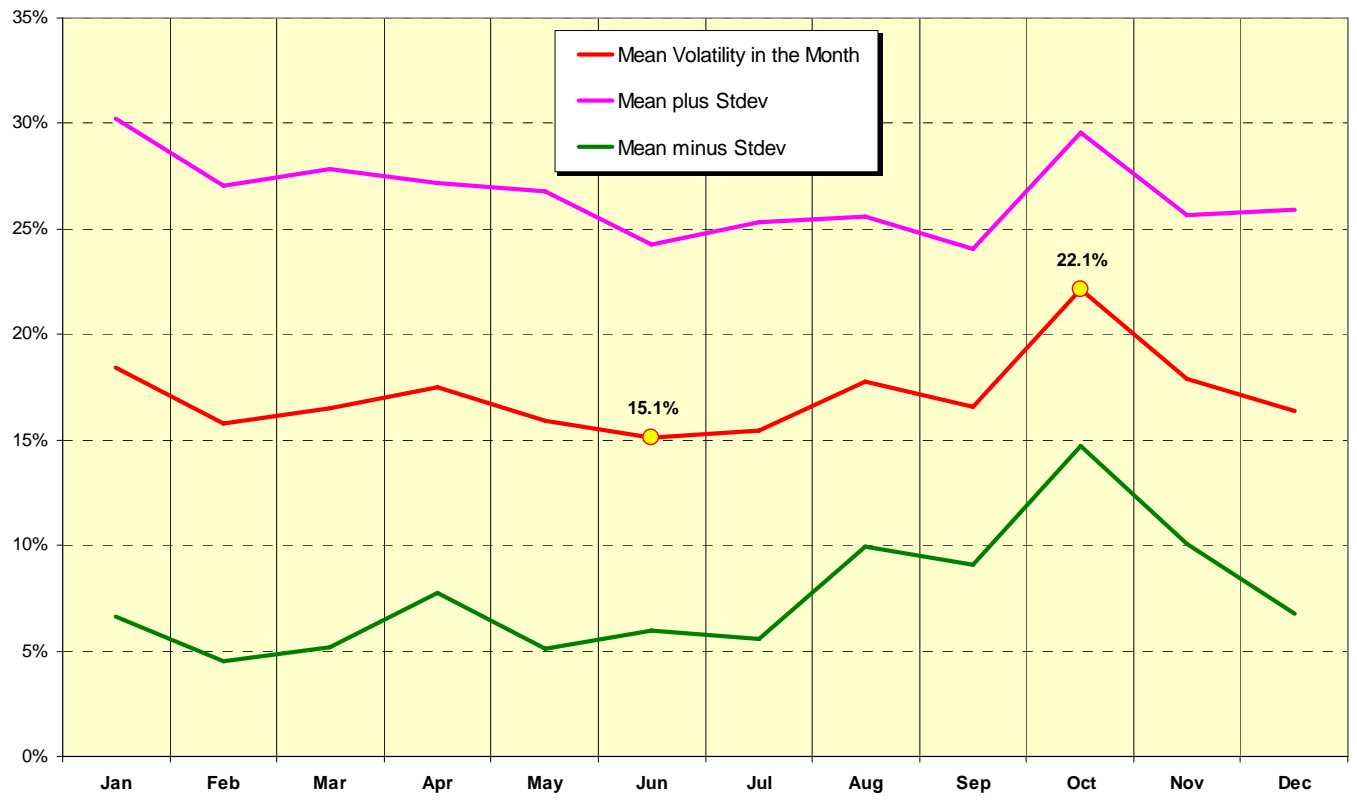

Figure 9: Monthly volatilities of the total return index

Volatilities were estimated using the daily total return index from 1984 to 2005 . The estimate for each month was the prior 30 day volatility. The graph shows that volatility estimates peak in October at an average of $22 \%$ off the mid year lows of $15 \%$. This has a significant impact on the prices of put options. 


\section{Table 3: Value of put options using various} parameters.

The table shows that the cost of purchasing a 30 day put in August with a volatility of $15 \%$ plus a 30 day put in October with a volatility of $22 \%$ would be $3,67 \%$. A better strategy would be to purchase a 180 day put in July for $2,67 \%$ and sell this in November for around $2,23 \%$, making the strategy almost costless.

\begin{tabular}{llll}
\hline & A & B & C \\
\hline Risk free rate & $7 \%$ & $7 \%$ & $7 \%$ \\
Spot & 100 & 100 & 100 \\
Strike & 100 & 100 & 100 \\
Volatility & $15 \%$ & $15 \%$ & $22 \%$ \\
Days & 30 & 180 & 30 \\
Price & 1,44 & 2,67 & 2,23 \\
\hline
\end{tabular}

Table 3 shows that the cost of purchasing a 30 day put in August with a volatility of $15 \%$ plus a 30 day put in October with a volatility of $22 \%$ would be $3,67 \%$. A better strategy would be to purchase a 180 day put in July for $2,67 \%$ and sell this in November for around $2,23 \%$, making the strategy almost costless.

\section{CONCLUSIONS}

Following Jacobsen and Bouman (2001) and Lucey and Whelan (2002) this study found evidence of seasonality in the JSE total return index over the period 1925 - 2005, with June and October showing the lowest average returns and December and January the highest. A trading rule which bought equity in December and switched to cash for the months of September, October and November resulted in the optimal performance over the period 1959-2005, outperforming the buy-and-hold the index.

A (more realistic) strategy of purchasing 31 day ATM puts in August and October was found to significantly out-perform the buy-and-hold the index by an average annual amount of around $1 \%$. This strategy was better than a crash protection strategy of purchasing cheaper out-the-money puts in these two months. The strategy was also found to be robust in that it persisted over the full data analysis period 1925-2005 and for the period 1985-2005.

An analysis of the index daily volatility showed a peak in October averaging 22\% over the period 1985-2005, with low volatilities in June/July of around $15 \%$. These differences were found to be statistically significant. A strategy of purchasing a 180 day put in July and selling this in November was postulated as being (almost) zero cost and therefore optimal.

\section{REFERENCES}

BBC Sport. 2001.

http://news.bbc.co.uk/sport1/hi/other_sports/1542263.s tm accessed 30 June 2005.

Beeders O. 2000. Seasonality on the Johannesburg Stock Exchange, Emory University Working Paper, http://www.economics.emory.edu/Working_papers/wp/ beelders_00_11_cover.html, accessed 27 July 2005.

Canestrelli E and Ziemba W. 2000. Seasonal anomalies in the Italian stock market 1973-1993. In Security Market Imperfections in World Wide Equity Markets. Cambridge: Cambridge University Press: 332-363.

Comolli L and Ziemba W. 2000. Japanese security market regularities. In Security Market Imperfections in World Wide Equity Markets. Cambridge: Cambridge University Press: 458-491.

Coutts JA and Sheik M. 2000. The January Effect and Monthly Seasonality in the All Gold Index on the Johannesburg Stock Exchange 1987-1997. Applied Economics Letters, 7: 489-492.

De Bondt $W$ and Thaler RH. 1985. Does the stock market overreact?, Journal of Finance, 40: 793-808.

Fama E. 1970. Efficient capital markets : A review of theory and empirical work, Journal of Finance, 25(2): 383-417.

Firer C, Sandler M and Ward M. 1992. Market timing: A worthwhile strategy?, Omega International Journal of Management Science, 20: 313-322.

Firer C and Staunton M. 2003. 102 Years of South African financial market history, Investment Analysts Journal, 56:57-65.

Hanson NH. 1984. Portfolio Insurance. New York: MacGraw-Hill.

Ho Y-K. 1990. Stock return seasonalities in Asia Pacific markets. Journal of International Financial Management and Accounting, 2(1): 47-77.

Jacobsen B and Bouman S. 2001. Sell in May and go away ; the Halloween indicator revisited. Available at SSRN: http://ssrn.com/abstract $=76248$ or DOI: 10.2139/ssrn.76248

Jeffery $\mathrm{RH}$. 1984. The folly of stock market timing. Harvard Business Review, 62: 102-110. 
Lucey BM and Whelan S. 2002. Monthly and semiannual seasonality in the Irish equity market 19342000. Working paper,

http://ssrn.com/abstract=298045.

Mills T and Coutts J. 1995. Calendar effects in the London Stock Exchange FT-SE Indices. The European Journal of Finance, 1: 79-93.

Riepe M. 1998. Is publicity killing the January effect? Journal of Financial Planning, 11 (February): 64-70.

Riepe M. 2001. The January effect; Not dead yet but not at all well. Journal of Financial Planning, 14, January: 44-47.

Rozeff M and Kinney W. 1976. Capital market seasonality - the case of stock returns. Journal of Financial Economics, 3: 379-402.

Robins EM, Sandler M and Durand F. 1999. Interrelationships between the January effect, market capitalisation and value investment strategies on the JSE. Investment Analysts Journal, 50: 53-64.

Sullivan, Timmerman and White 2001. Dangers of data driven inference: The case of calendar effects in stock returns. Journal of Econometrics, 105(1): 249-286.

Van Den Berg W and Wessels R. 1985. Stock Market Seasonality and Taxes: An Examination of the Tax Loss Selling Hypothesis. Journal of Business, Finance and Accounting, 12(4): 515-530.

Waksman G, Sandler M, Ward M and Firer C. 1997. Market timing on the Johannesburg Stock Exchange using derivative instruments. Omega International Journal of Management Science, 25(1): 81-91. 